

Webster Family Library of Veterinary Medicine Cummings School of Veterinary Medicine at Tufts University

\section{Westboro Road}

North Grafton, MA 01536 


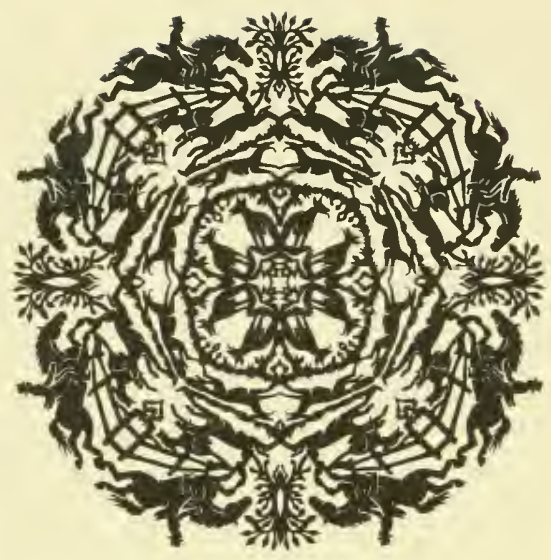

JOHN A.SEAVERNS 




\section{H O R S E S}

IN ACCIDENT AND DISEASE 
Edinburgh: Printed by George Waterston di Sons

FOR

DAVID DOUGLAS.

LONDON, - . . SIMPKIN, MARShaLl, haMLLTON, KENT, AND CO, LIMHED. CAMBRIDGE, . . MACMILLAN AND BUWES.

GLASGOW, . . JAMES MIACLEHOSE AND SONS. 


\section{H O R S E S}

\section{IN ACCIDENT AND DISEASE}

NOTES AND SKETCHES

BY

J. ROALFE COX, F.R.C.V.S.

EDINBURGH: DAVID DOUGLAS MDCCCXCII.

NEW YORK: WM. R. JENKINS 



\section{P R E F A C E.}

In introdueing my Sketches of Horses in Aecident and Disease, I should explain, in excuse of their appearance, that they were not drawn originally with any idea of publication, and they are now offered in response to the solicitation of several professional friends. From my earliest association with the Veterinary profession I have made notes and sketches of prominent signs of suffering in horses, and I have learnt that many of these are forcibly enongh expressed in peculiar attitudes, if we only take the pains to read them. Fortunately, our patients never tell an untruth, and, with all the failings of their kind, they do not malinger; whilst their tale of disablement and pain, "though it hath no tongue, will speak with most miraeulous organ."

What I have seen, so have all old practitioners, and these will reeognise a true and mnexaggerated presentment of familiar cases, which may not be altogether uninteresting. But utility ean only serve the rising generation of Veterinary Surgeons, who have not yet come aeross the 
real article; and if to such I may happily be affording some help in their reading and their earlier practice, I shall have gained all I could hope from publicity. I have purposely abstained from any lengthened description of the disorders represented, because such is already so fully given in excellent works up to date.

\section{J. ROALFE COX.}

London, September 1892. 


\section{SKETCHES.}

CASE

I. CHOKING.

II. CHOKING.

III. STOPPAGE OF THE BOWELS.

IV. COLIC.

V. STRANGULATED BOWEL.

VI. STRANGULATED BOWEL.

VII. VOMITING.

VIII. STRANGULATED HEIINIA.

IX. RUPTURE OF STOMACH.

X. CONGESTION OF LUNGS.

XI. CALCULUS IN BLADDER.

XII. DISLOCATION OF PATELLA.

XIII. DISLOCATION OF HIP.

XIV. LAMINITIS.

XV. RUPTURE OF MUSCLE (FLEIOR METATALSI).

XVI. DROPPED ELBOW.

XVII. FRACTURE OF ELBOW.

XVIII. A "SHIVERER."

XIX. WRY NECK.

XX. TETANUS. 
SKETCHES.

CASE

XXI. MEGRIMS.

XXII. TUMUUR IN BRAIN.

XXIII. STOMACH S'TAGGERS.

XXIV. BROKEN BACK.

XXV. ARSENIC, POISONED BY.

XXVI. ARSENIC, UUTWARDLY APPLIED.

XXVII. ABSCESS A'T POLL-CURIOUS CASE.

IXVIII. OS'TEO SARCOMA OF JAW. 
密 


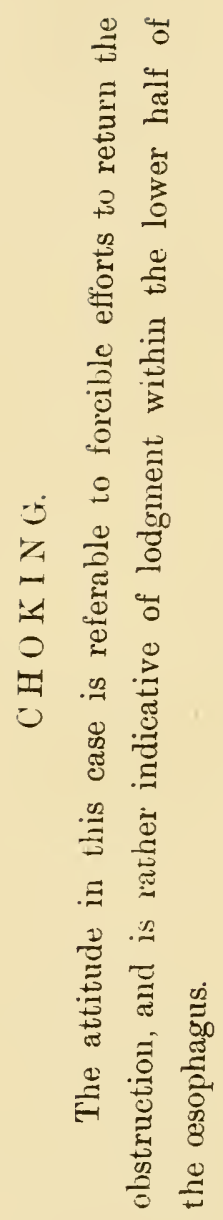




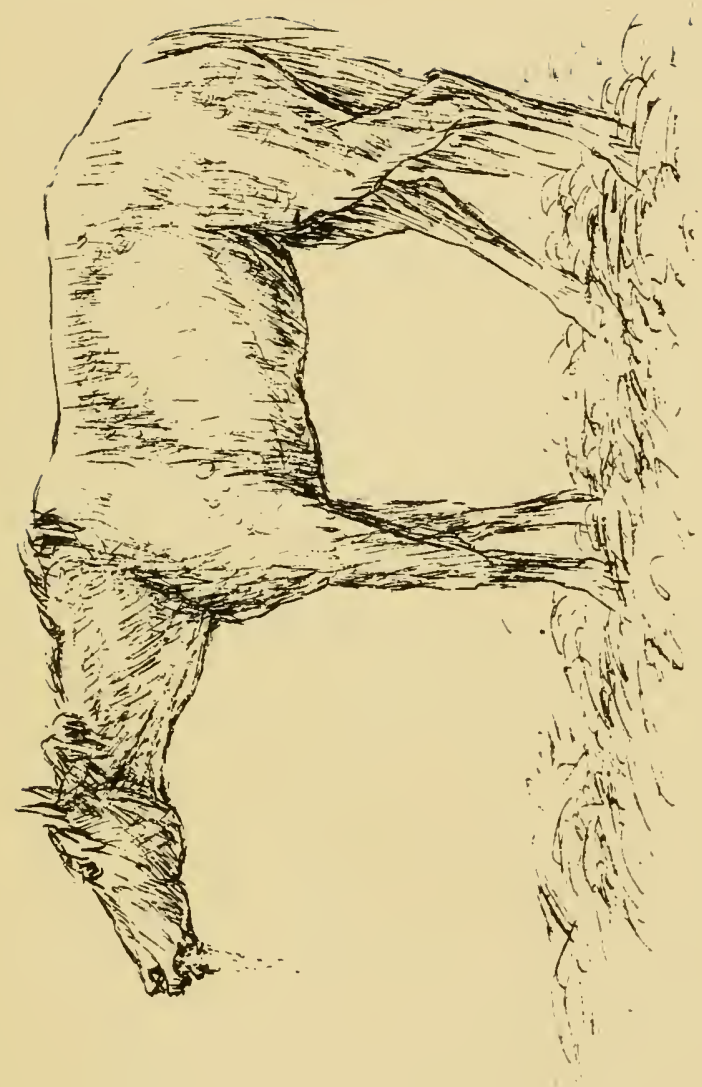



善 


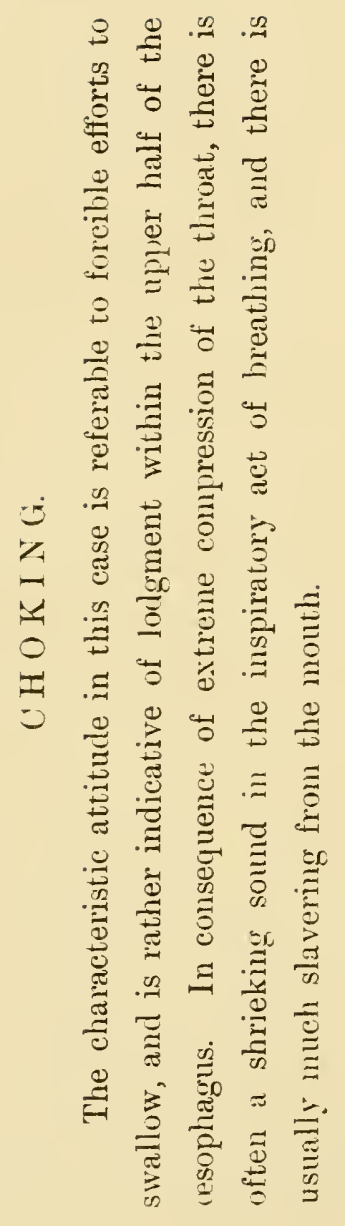




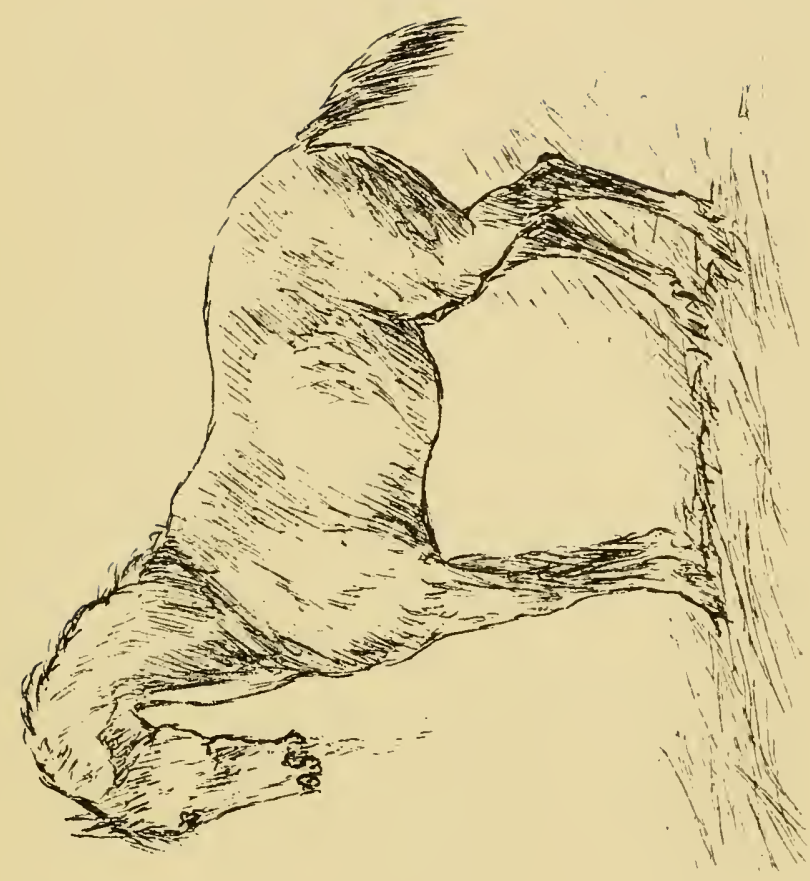



$コ$
絰
己 


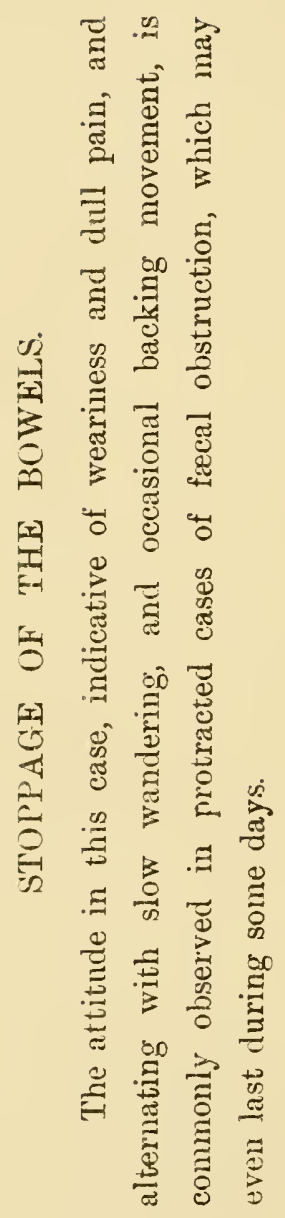




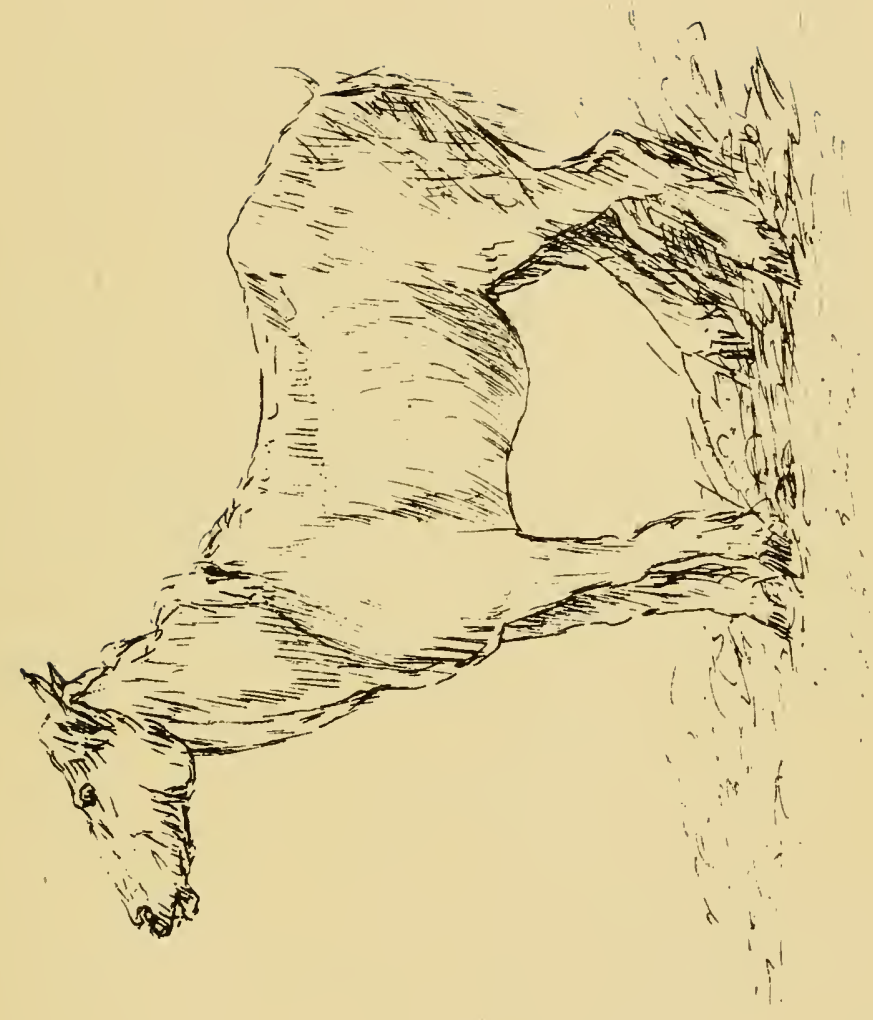



弪 


$$
\text { }
$$




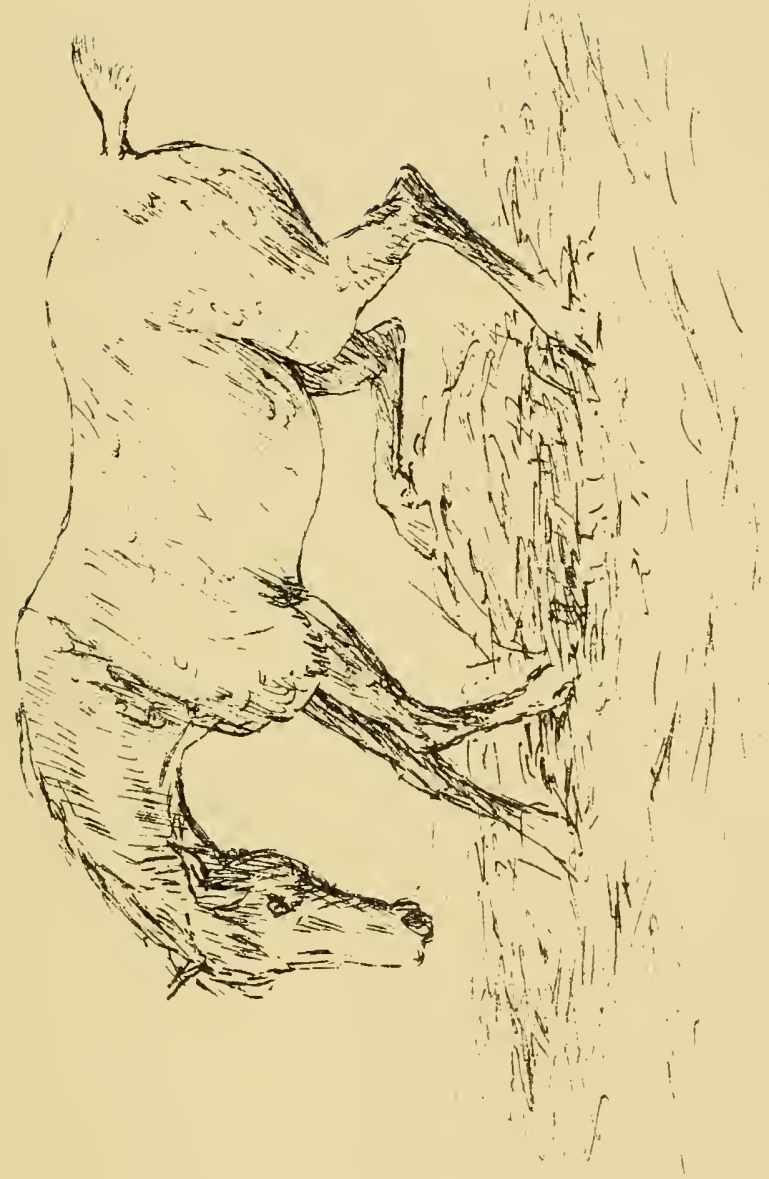



琶 


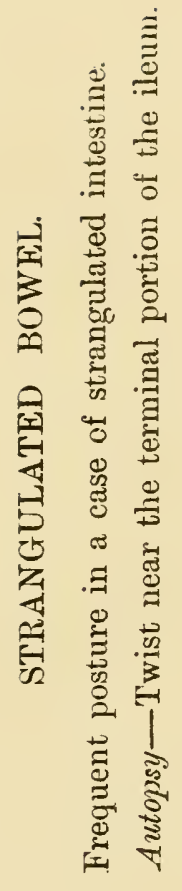




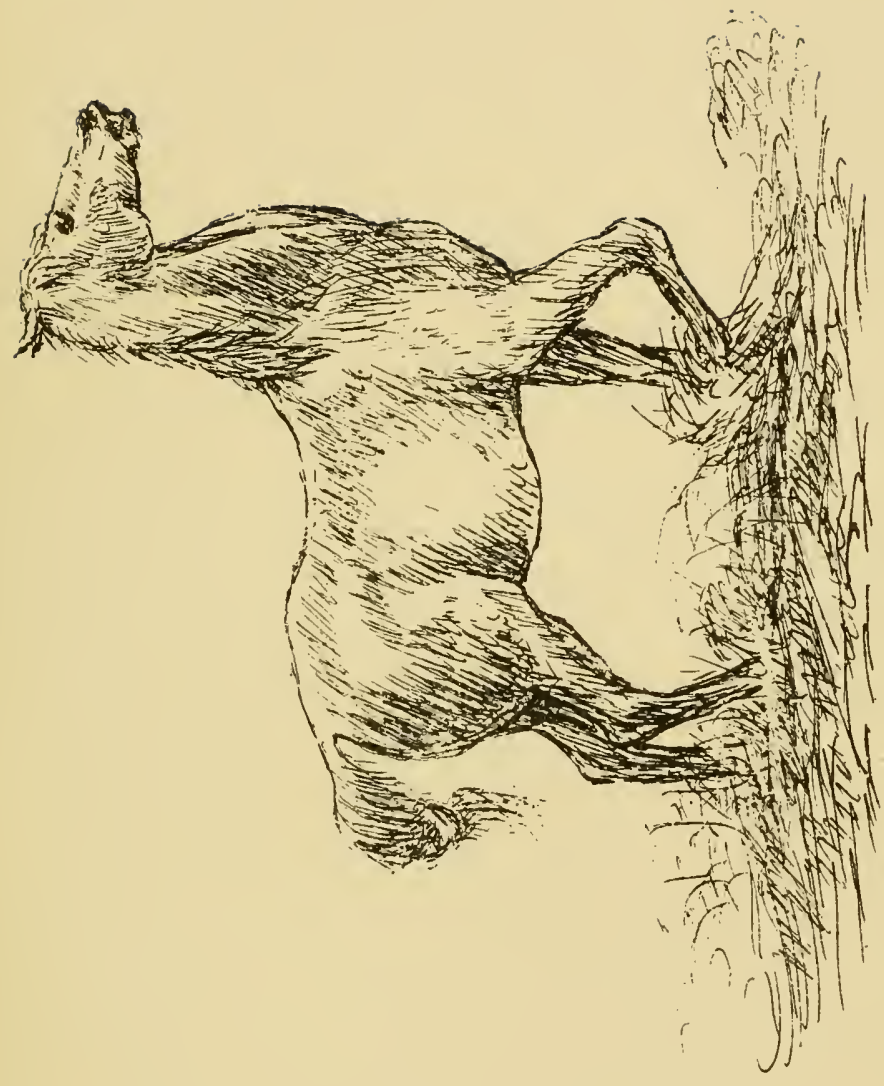



新 


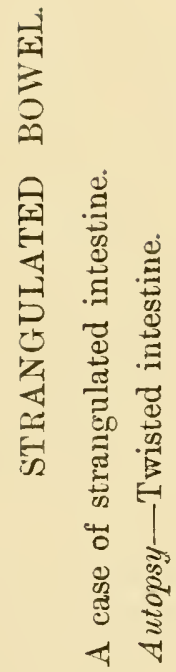




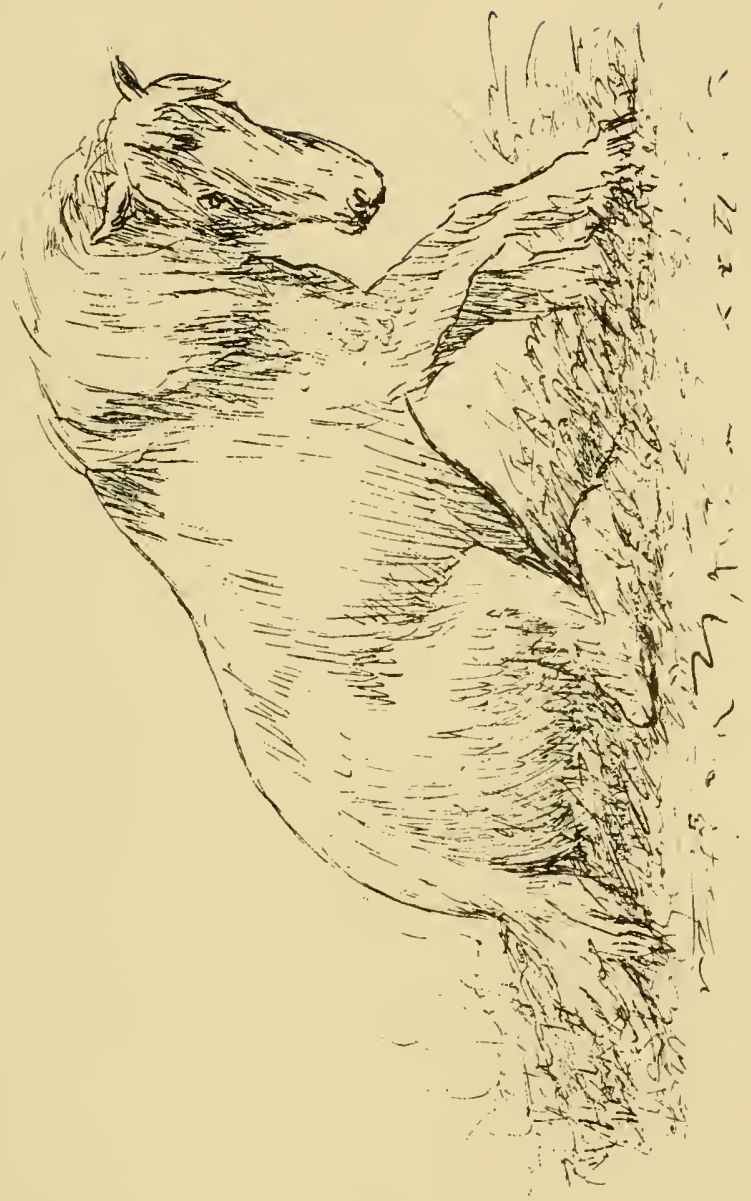



焉 


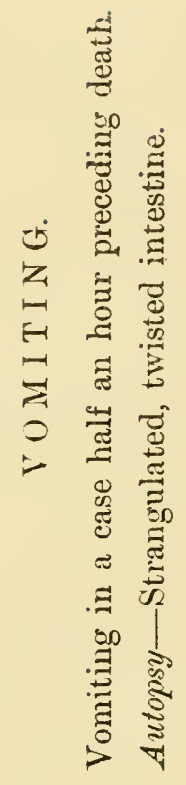




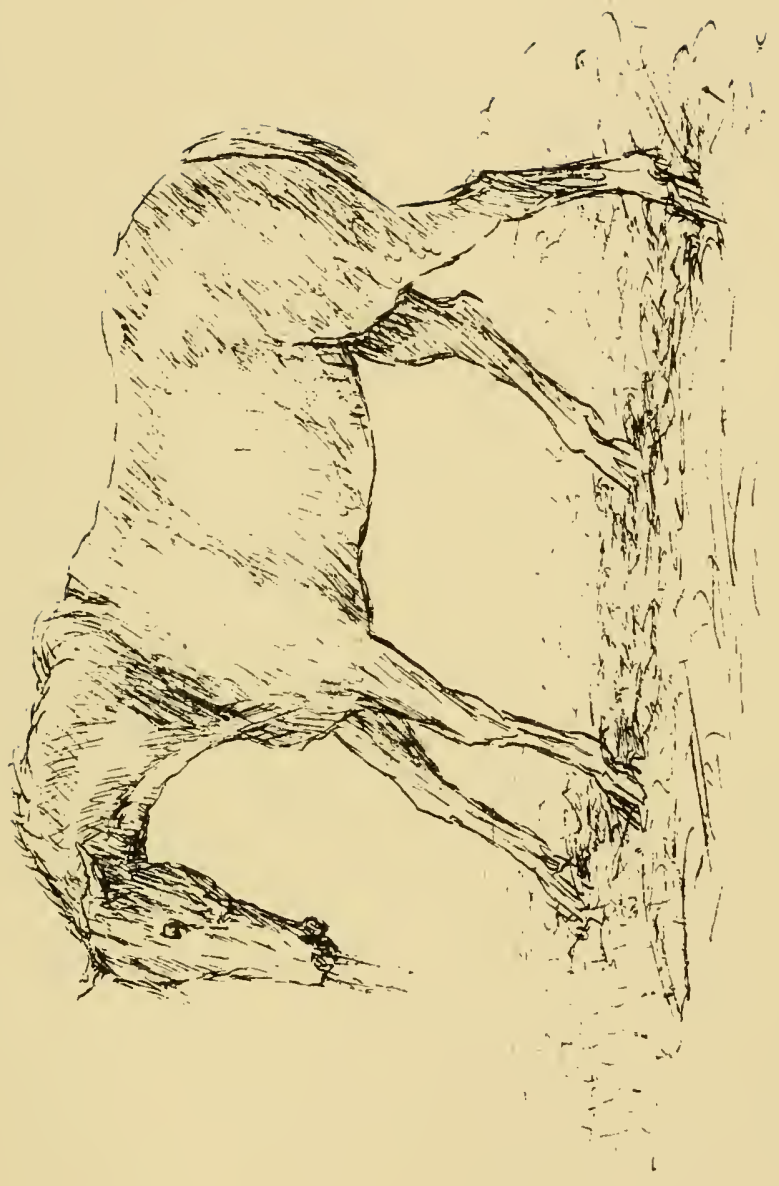





$$
\text { 息 }
$$




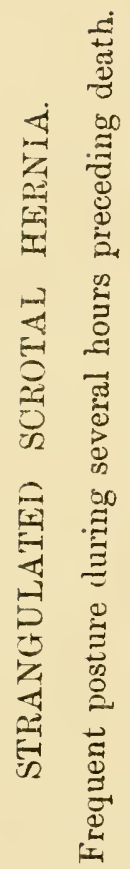




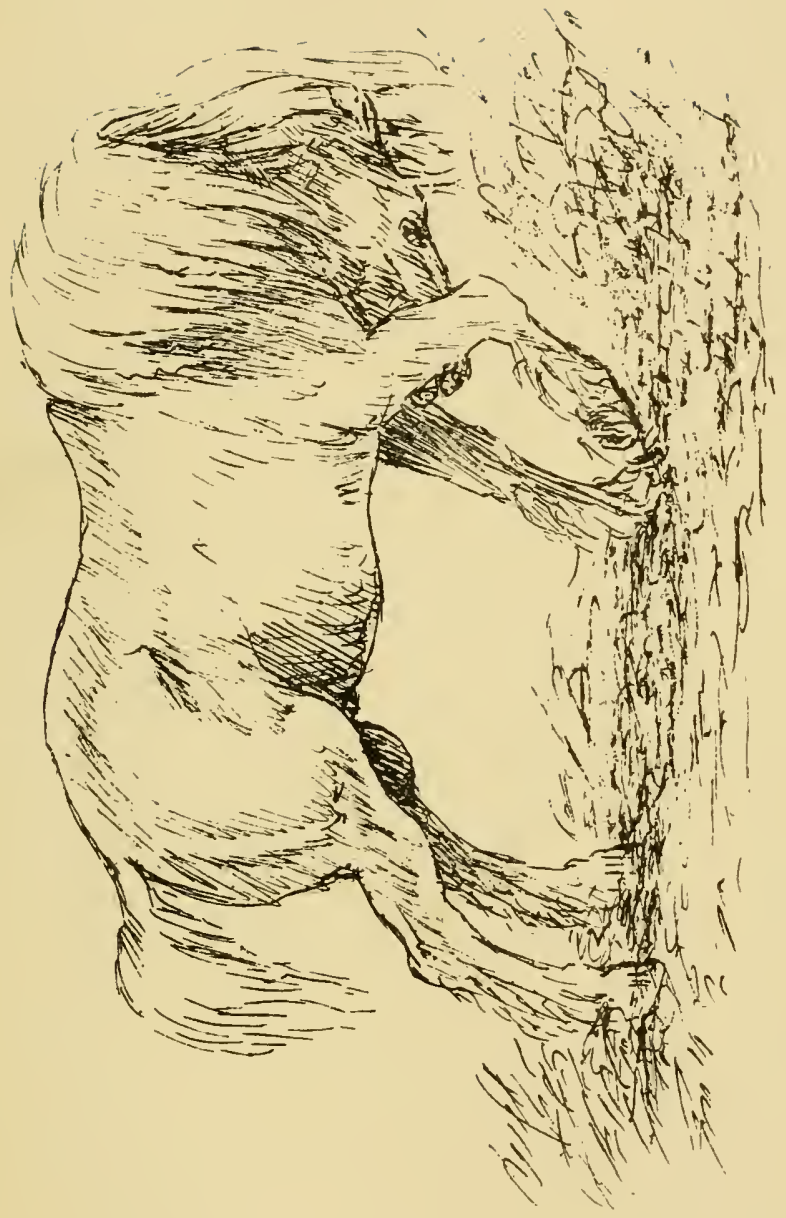





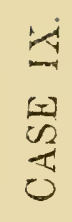




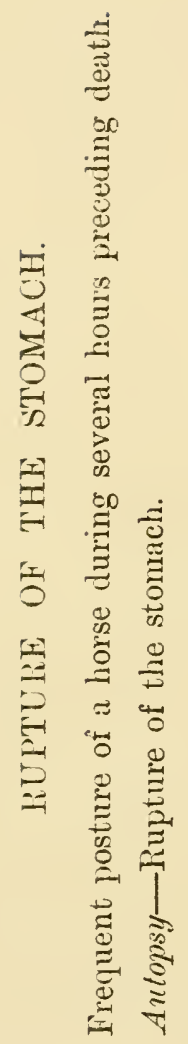




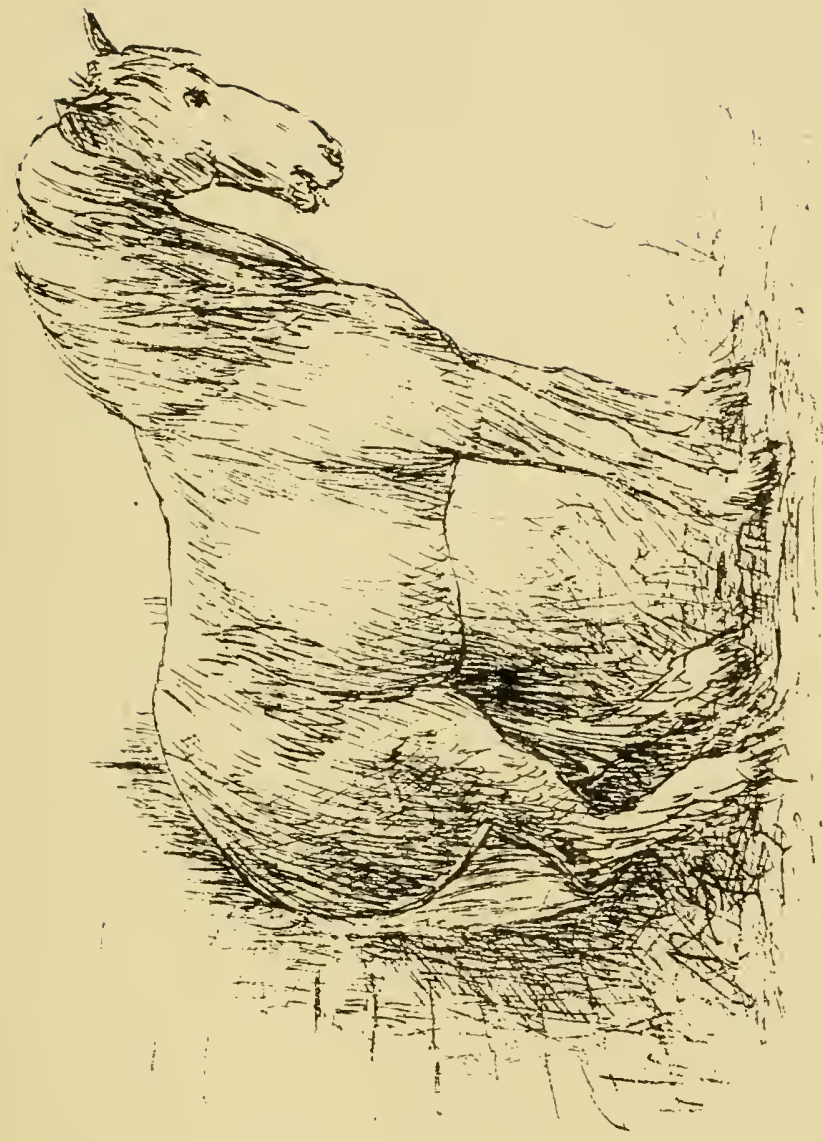



嫼 


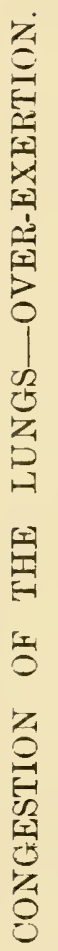




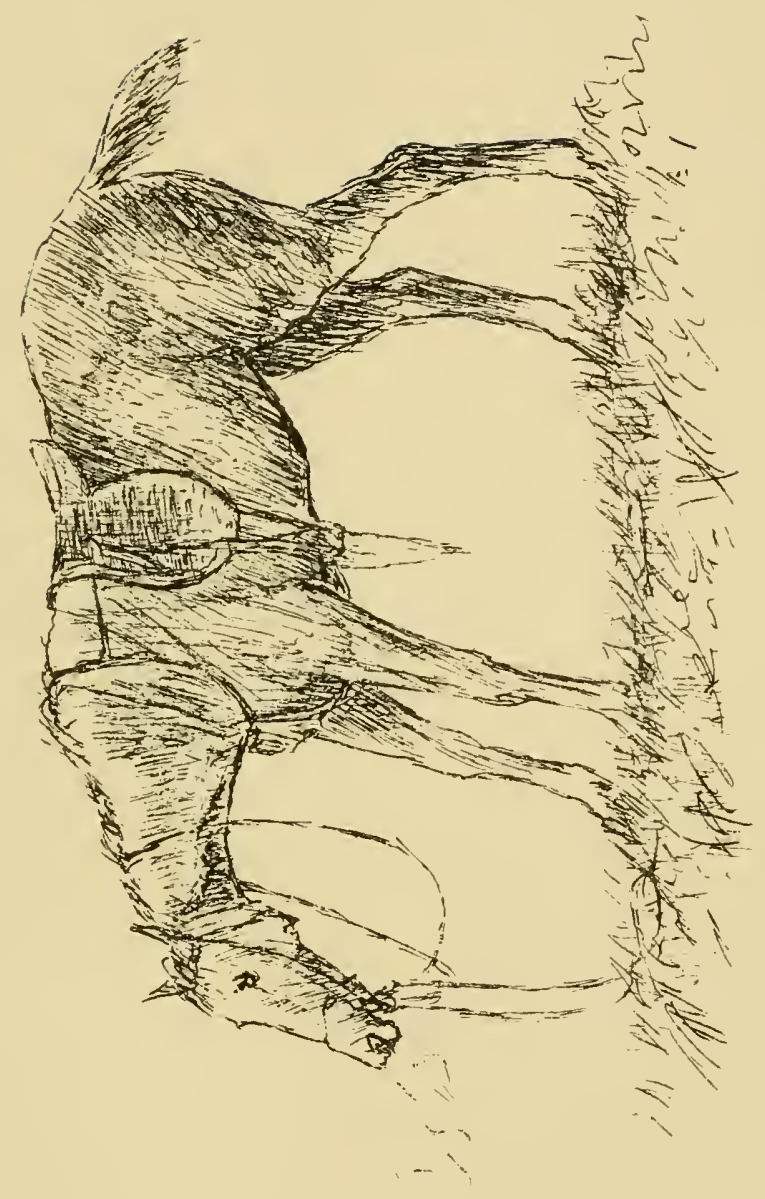





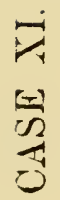




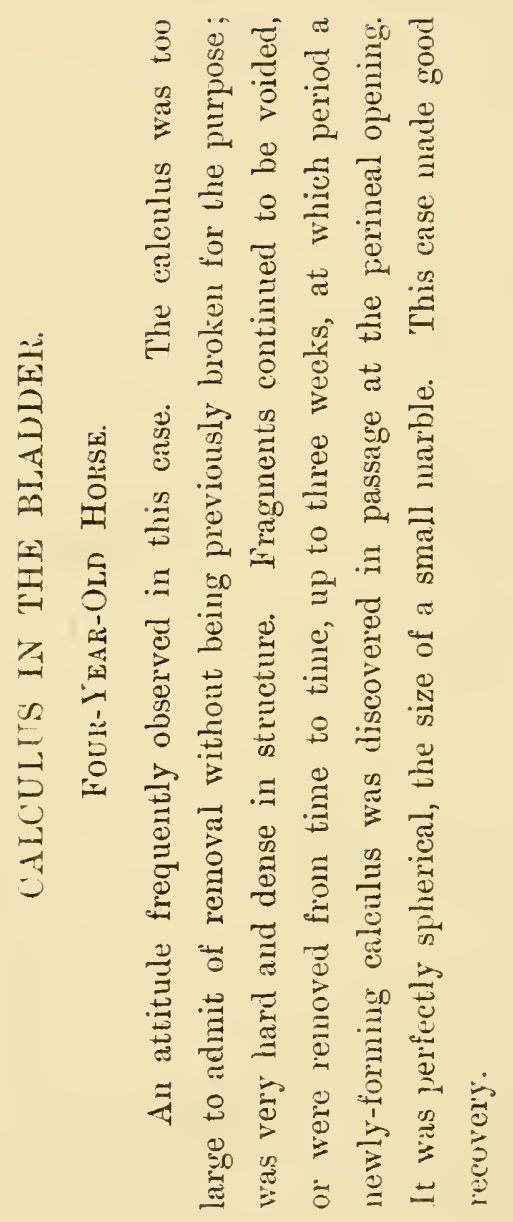




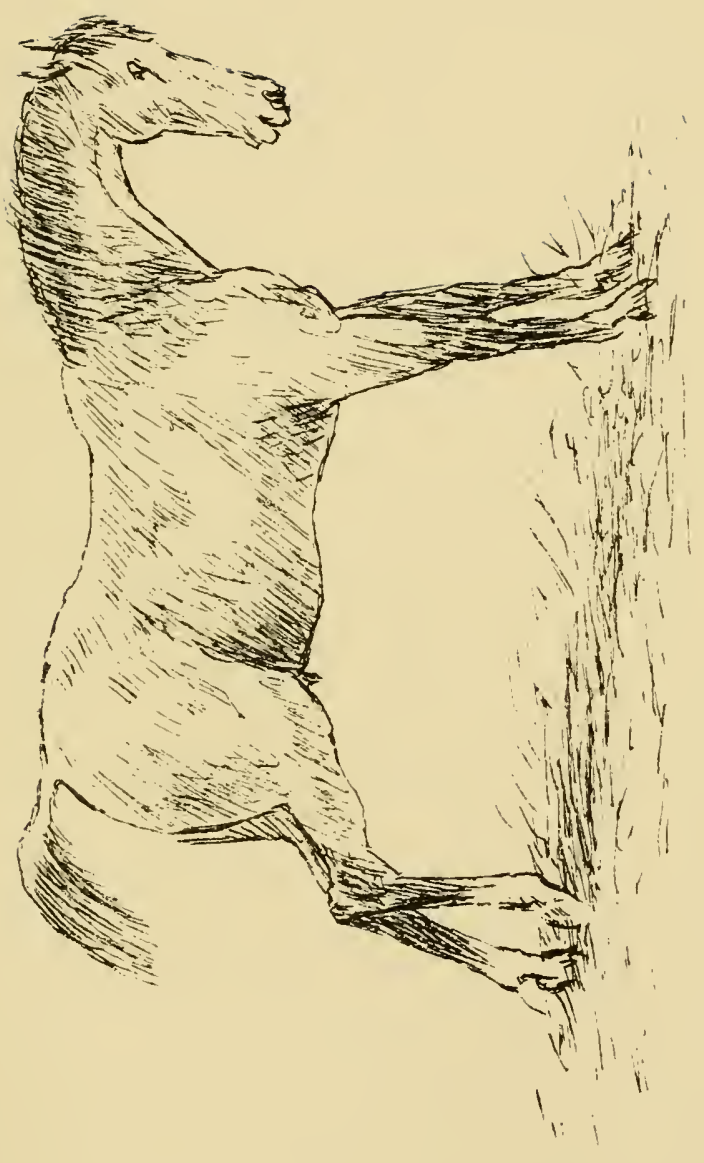





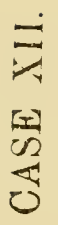




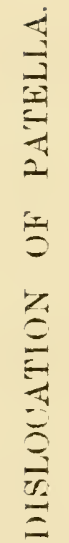




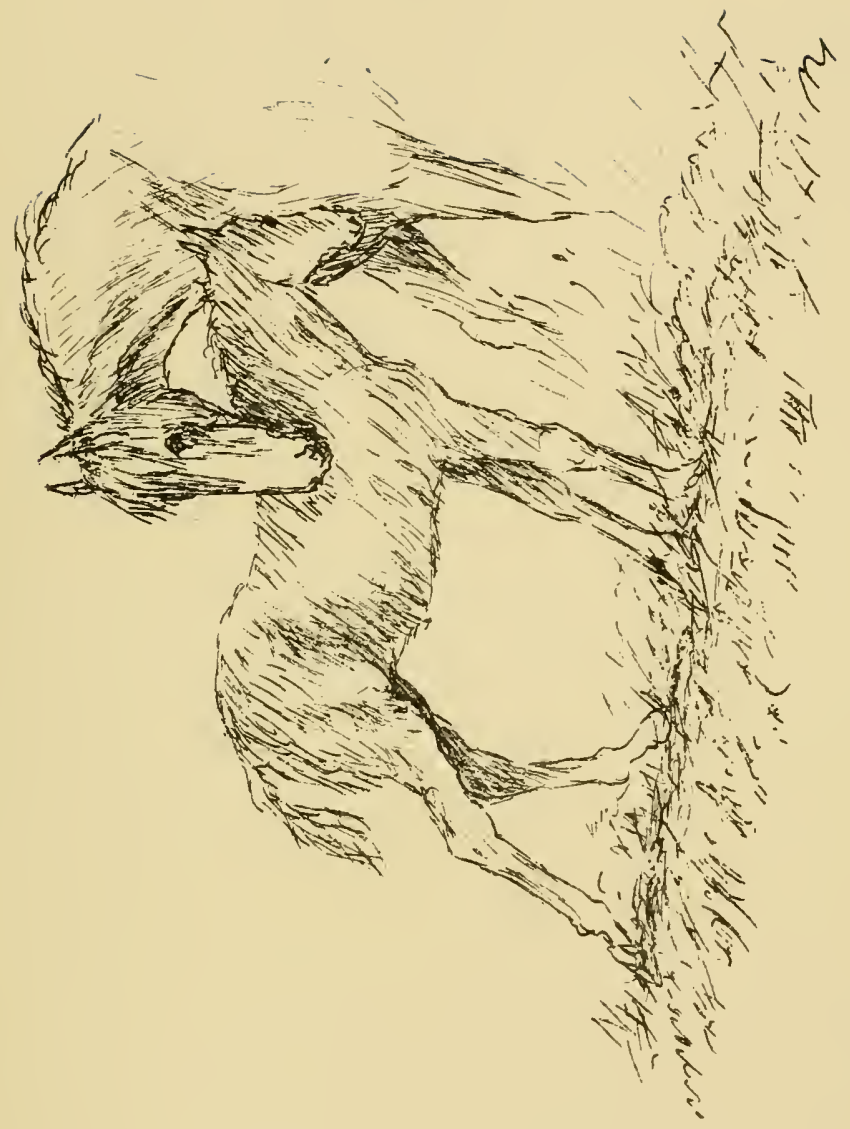



产 


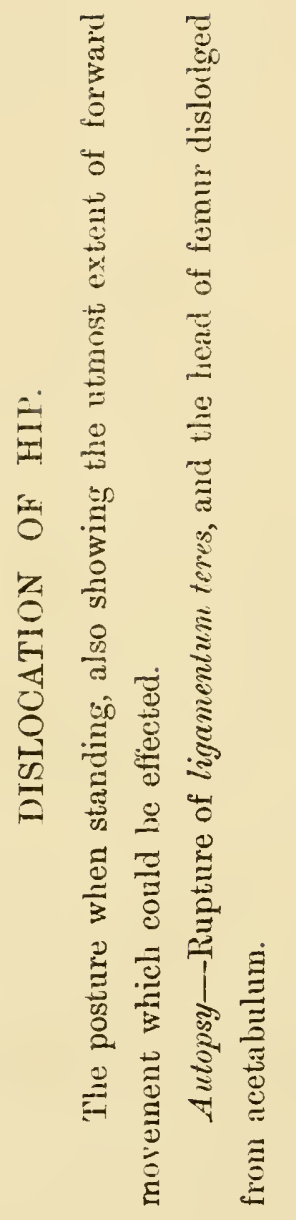




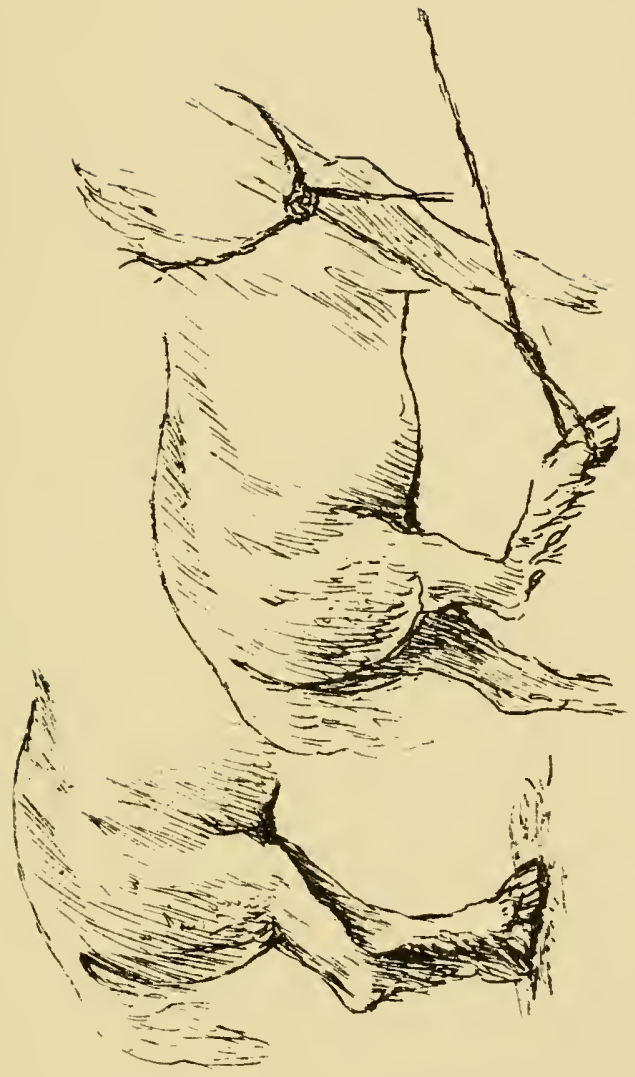



岩
䆓 


$$
\begin{aligned}
& \text { Ð } \\
& \sim \stackrel{0}{0} \\
& \text { 乙 } \\
& \text { - } \\
& \text { 远 } \\
& \sim \sqrt{\circ} \\
& \text { Ð }
\end{aligned}
$$




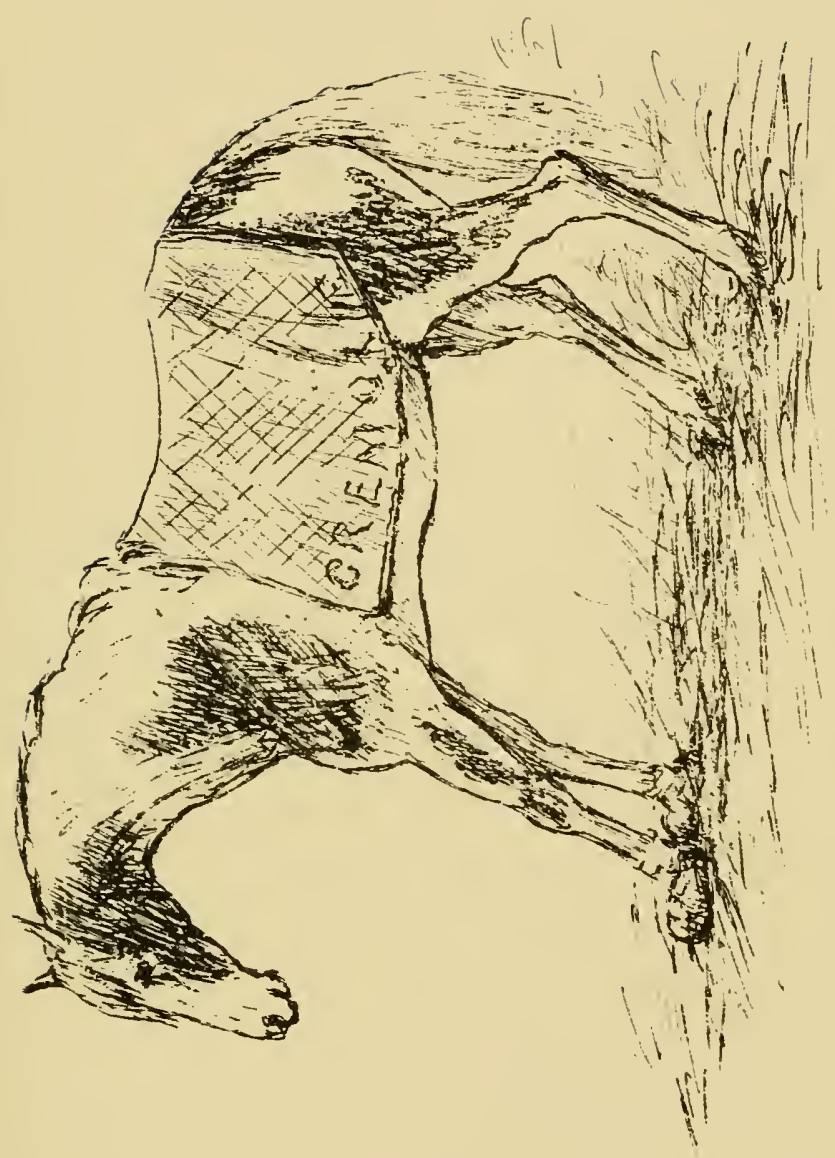



ㄹ.

昜 


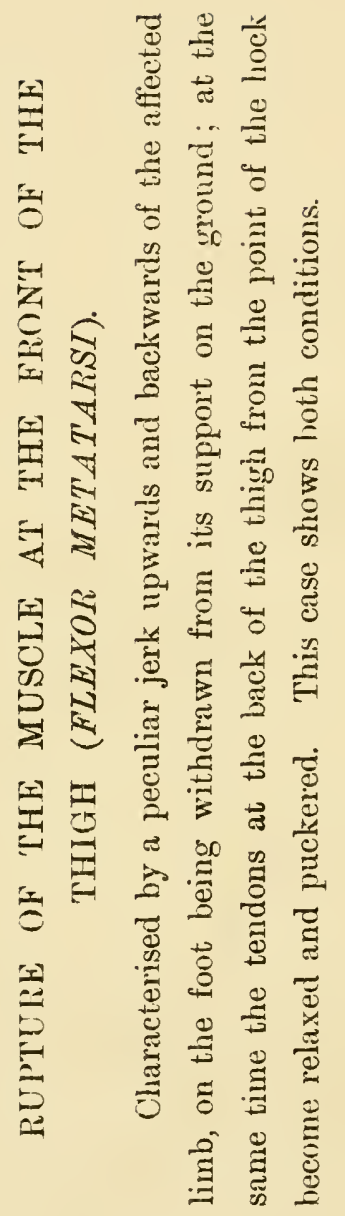




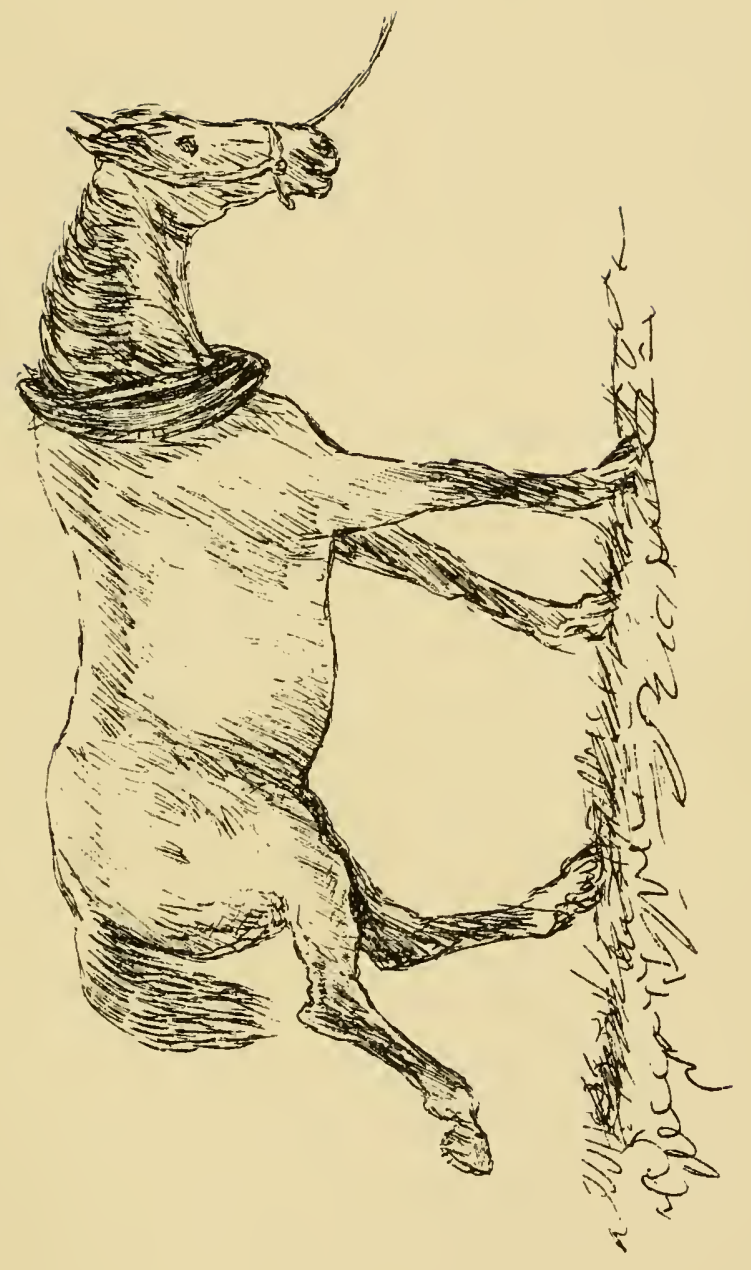



章 


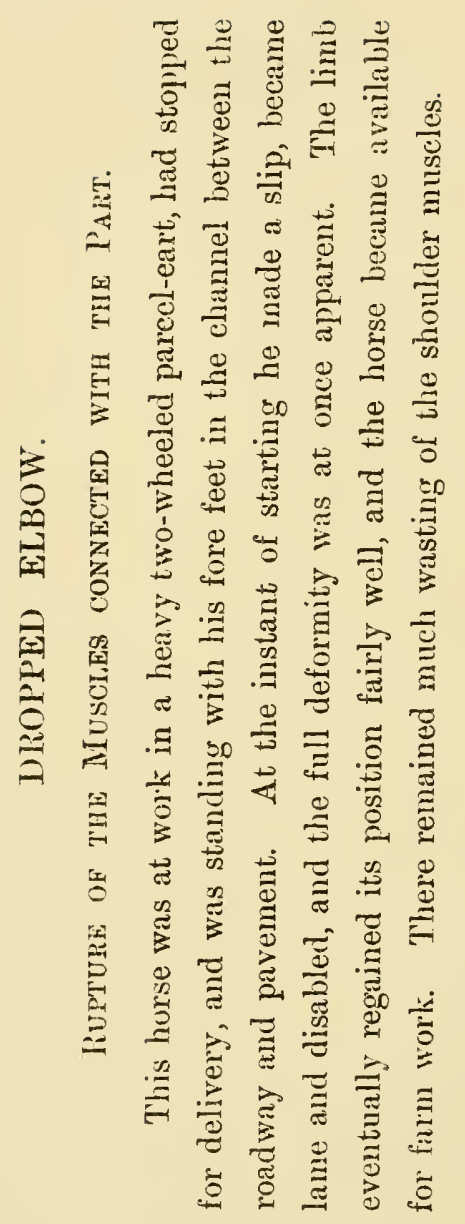




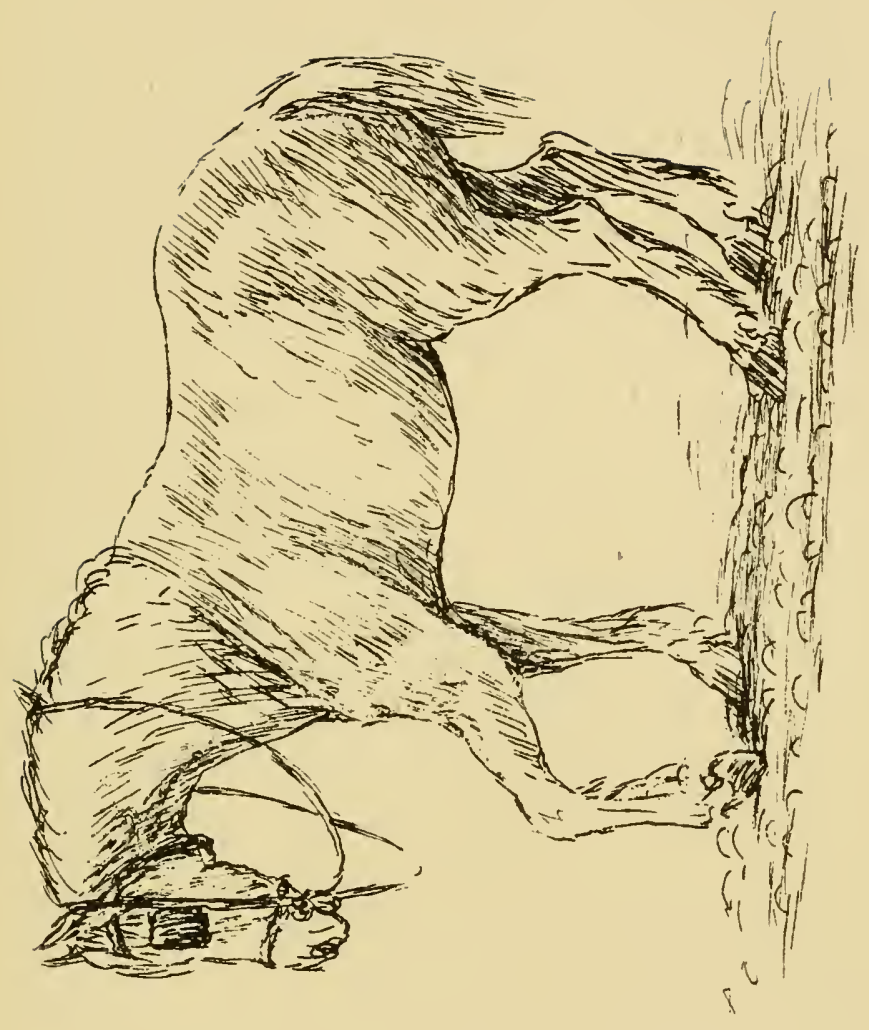



言 


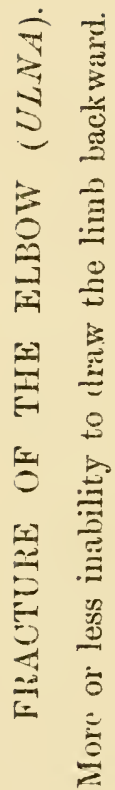




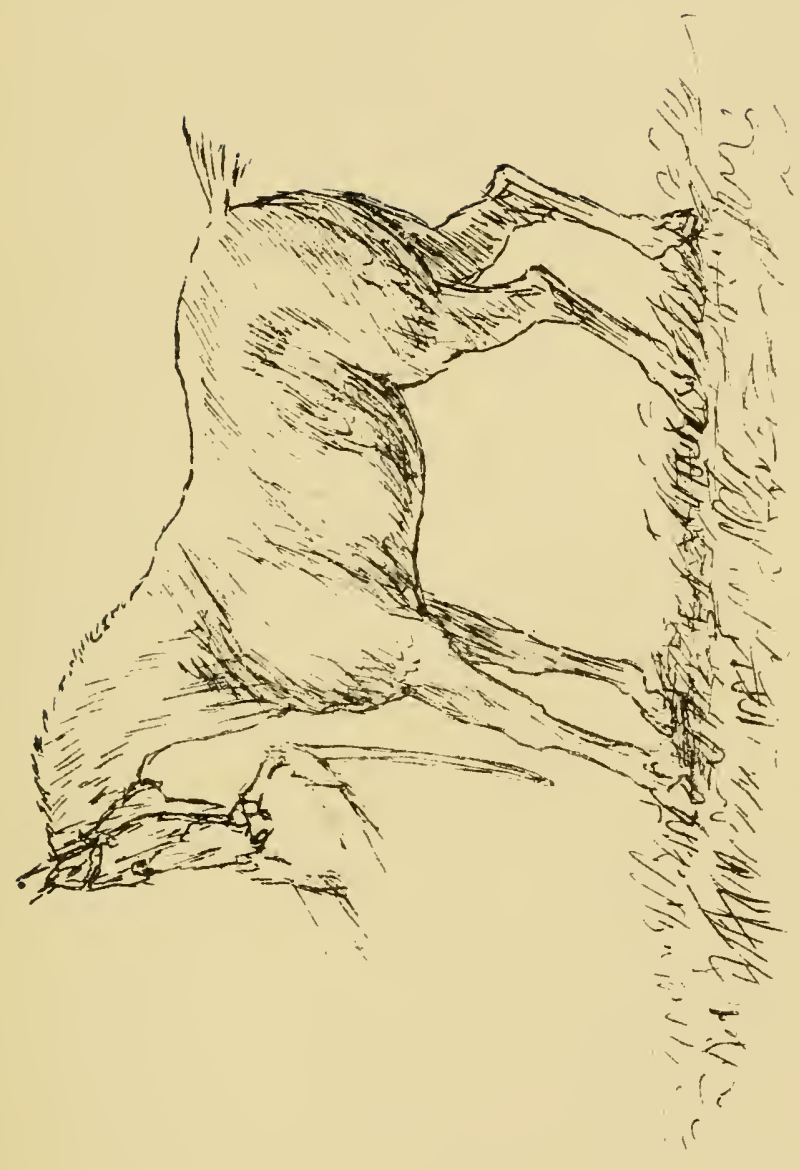





$$
\text { 严 }
$$




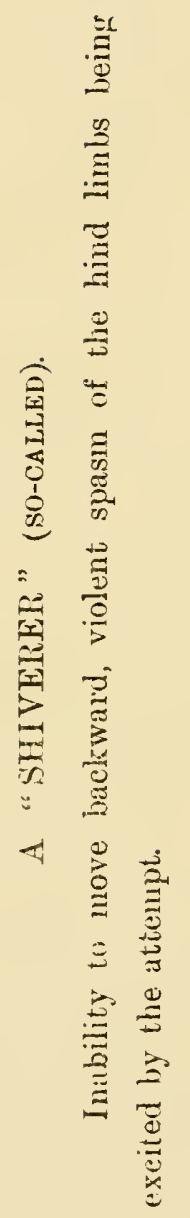




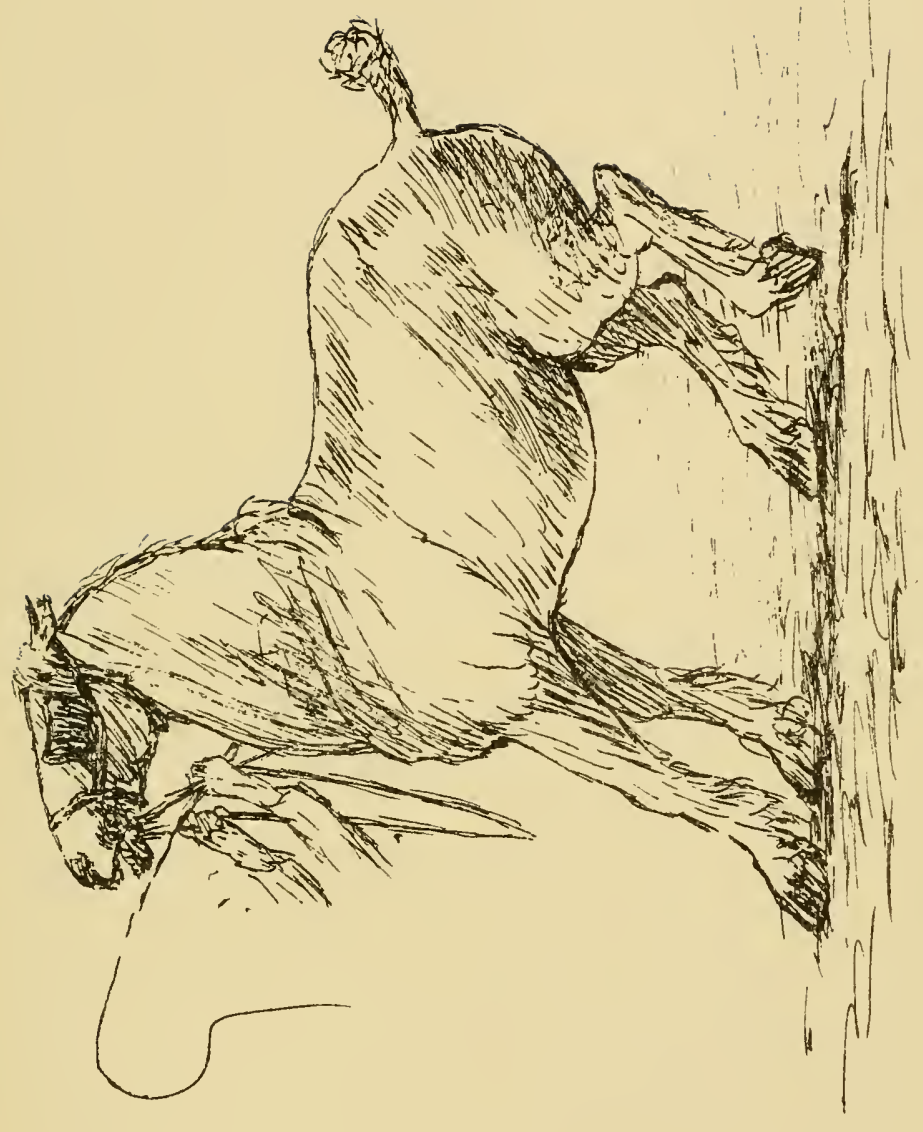



音

裁 


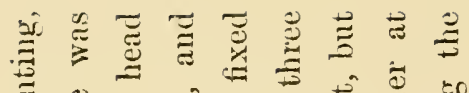

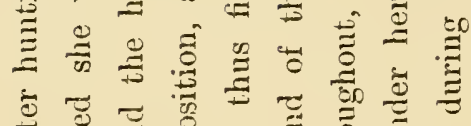

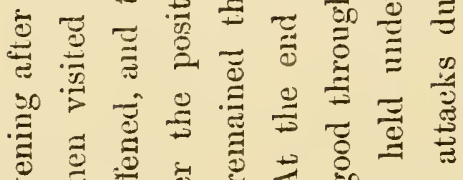

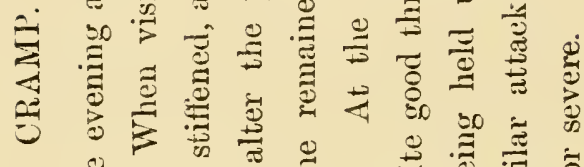

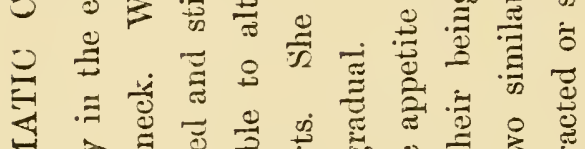

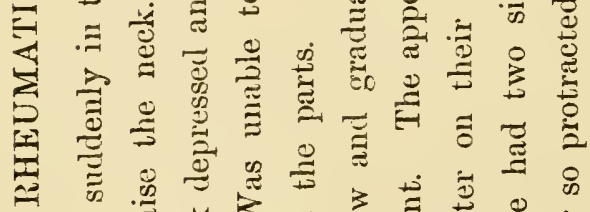

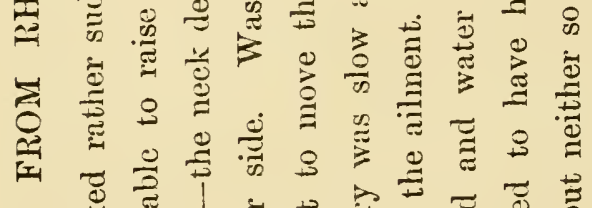

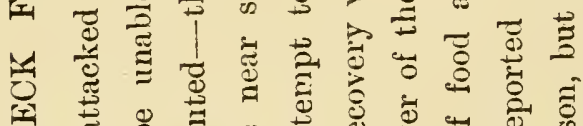

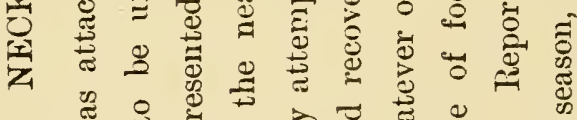

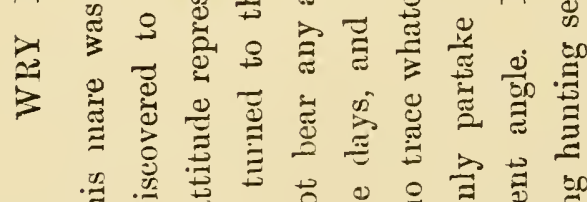

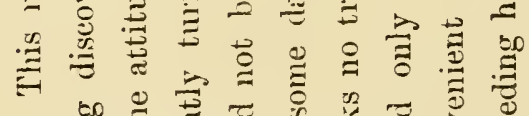

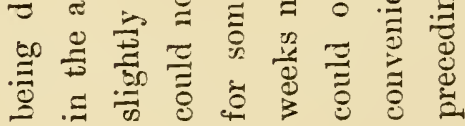




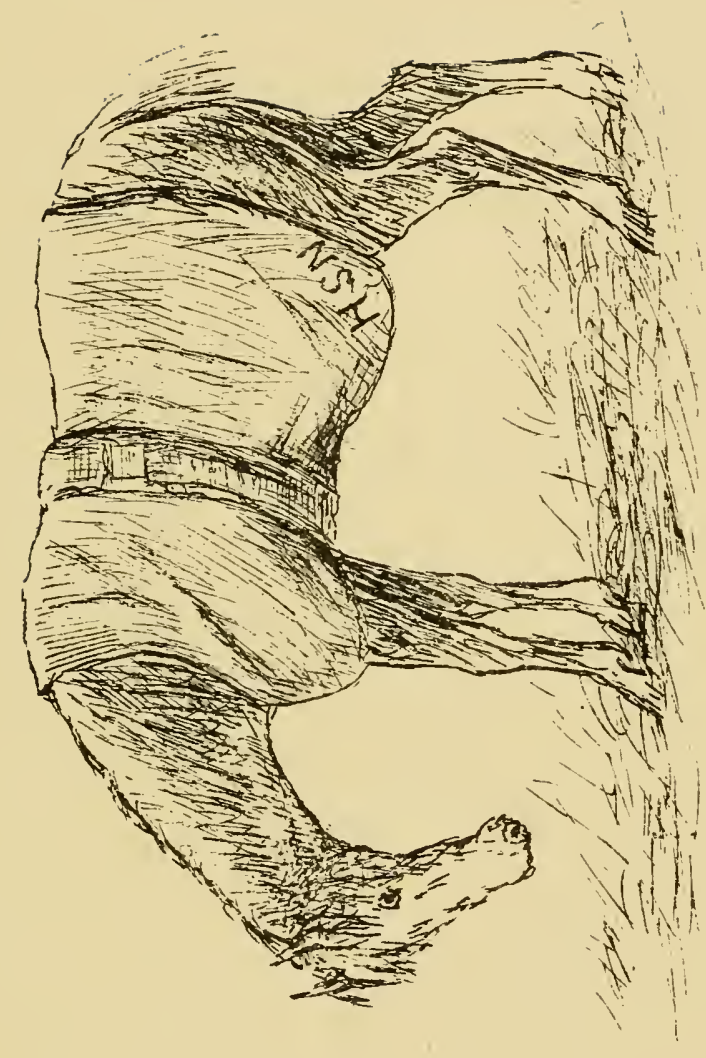





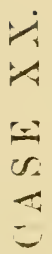


竞 


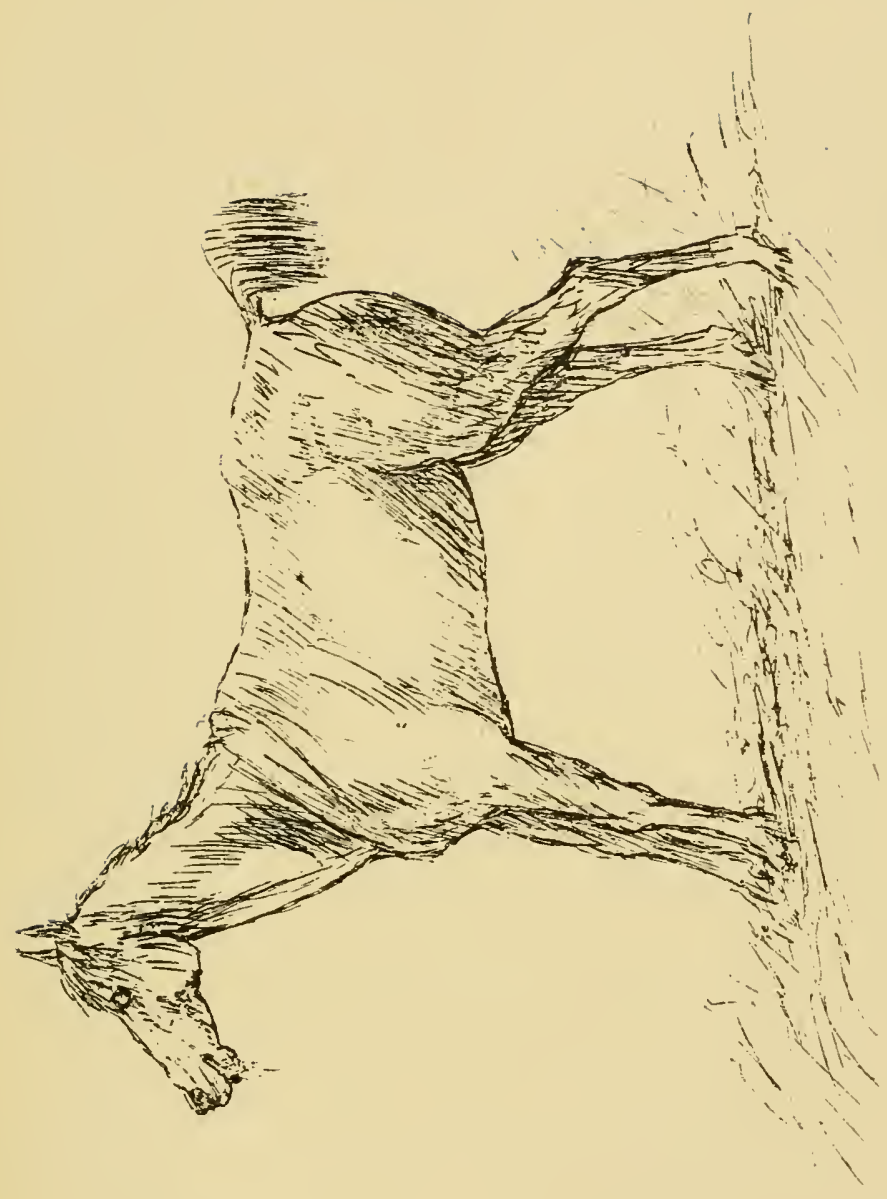



$\dot{3}$
4
4
0
0
0 
E 


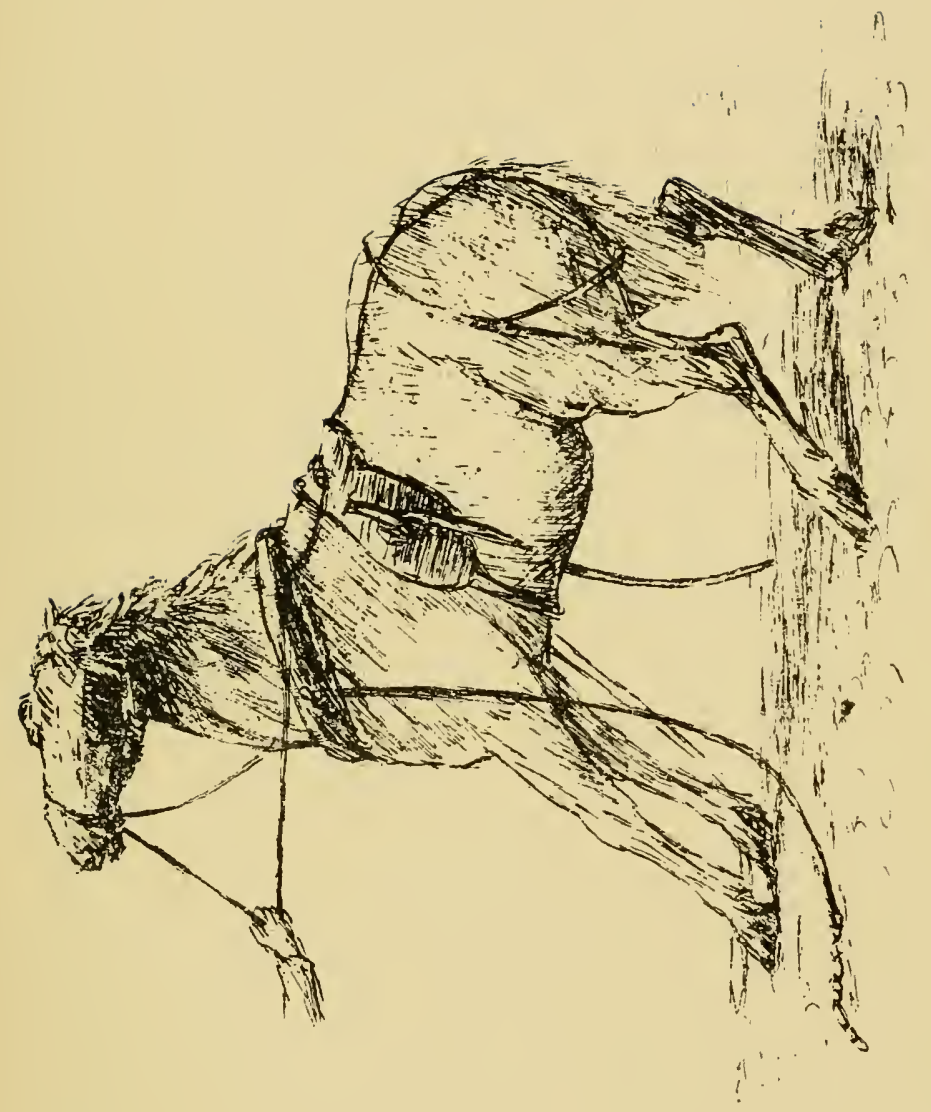



㴅 


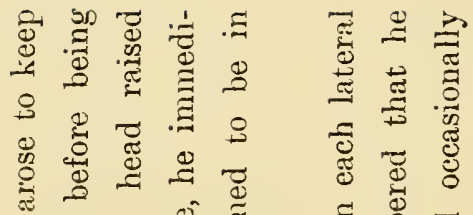

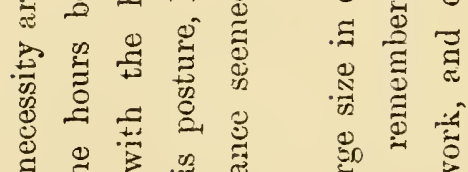

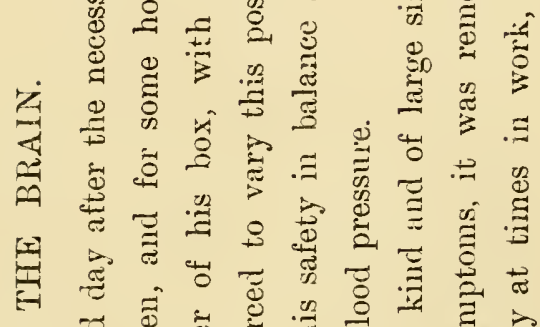

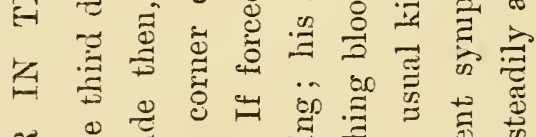

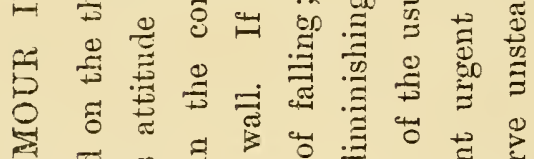

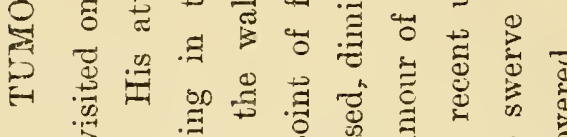

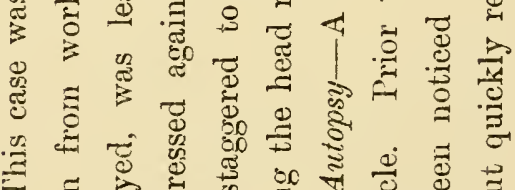

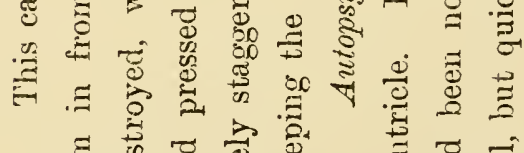

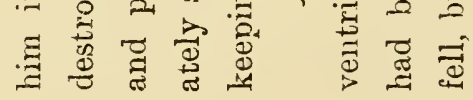




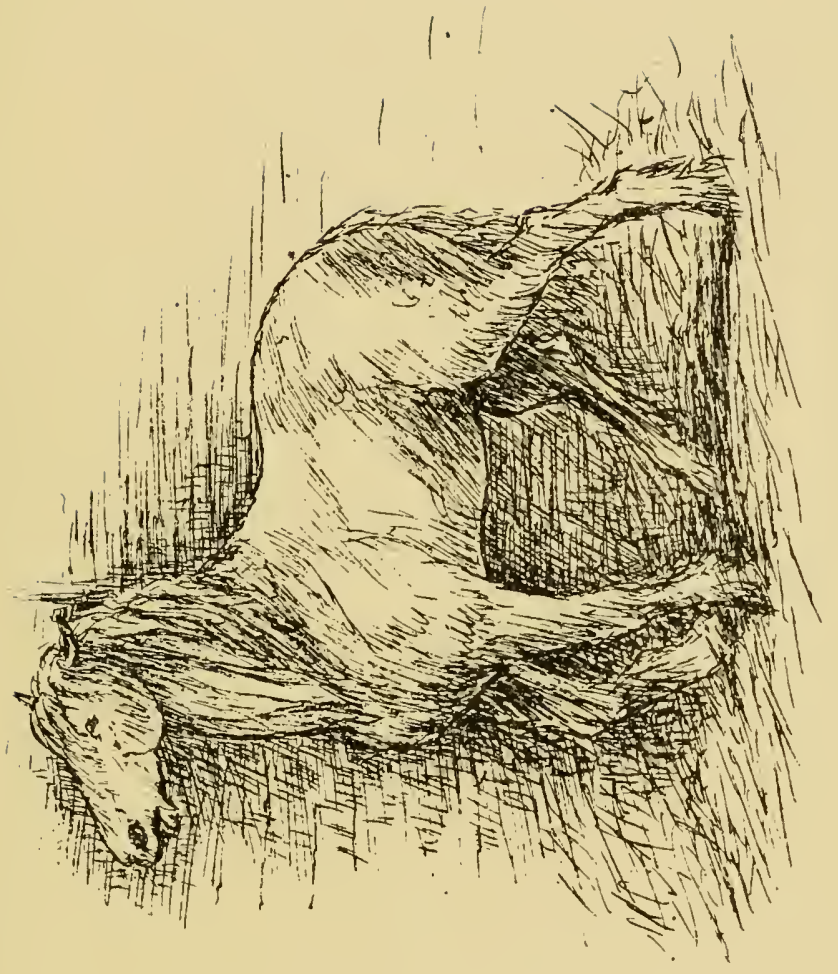



基 


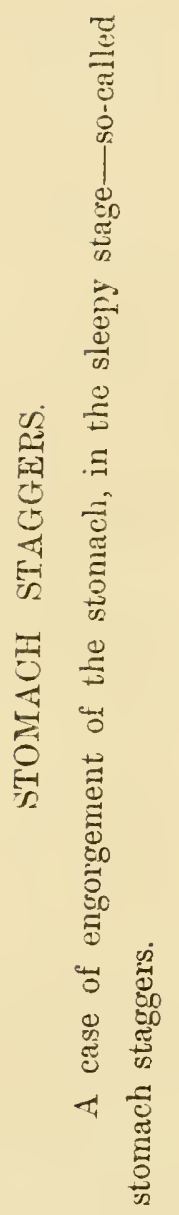




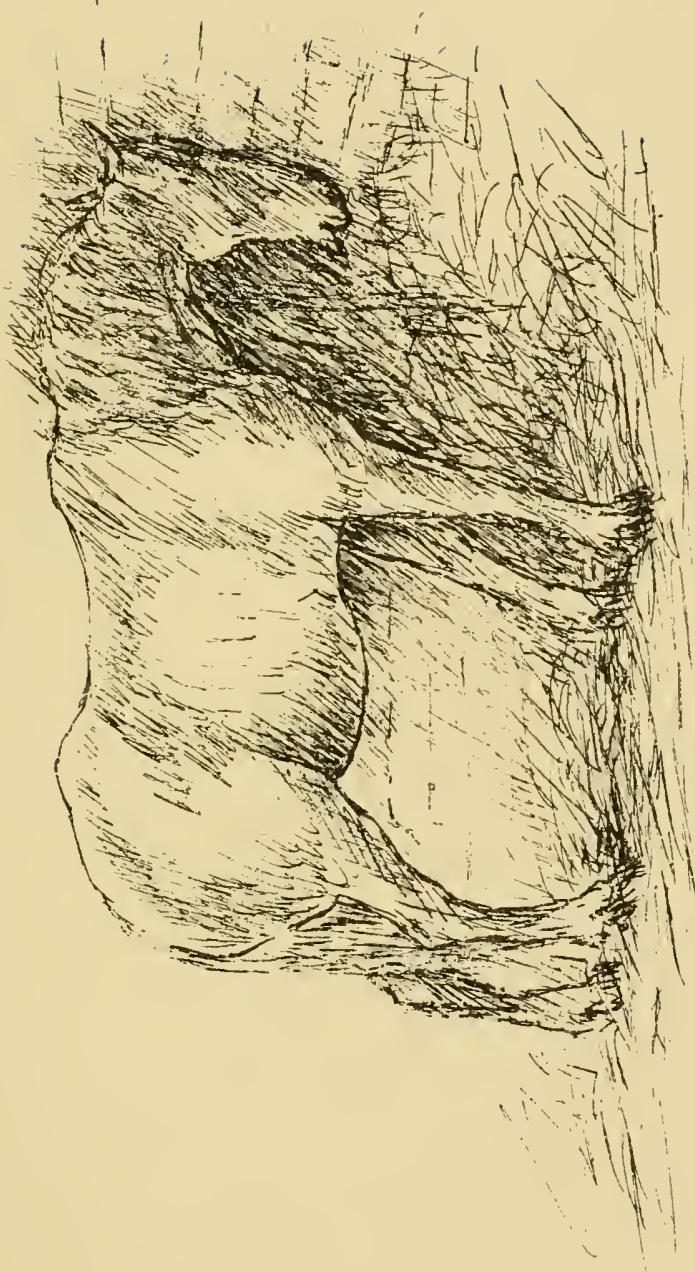



音 



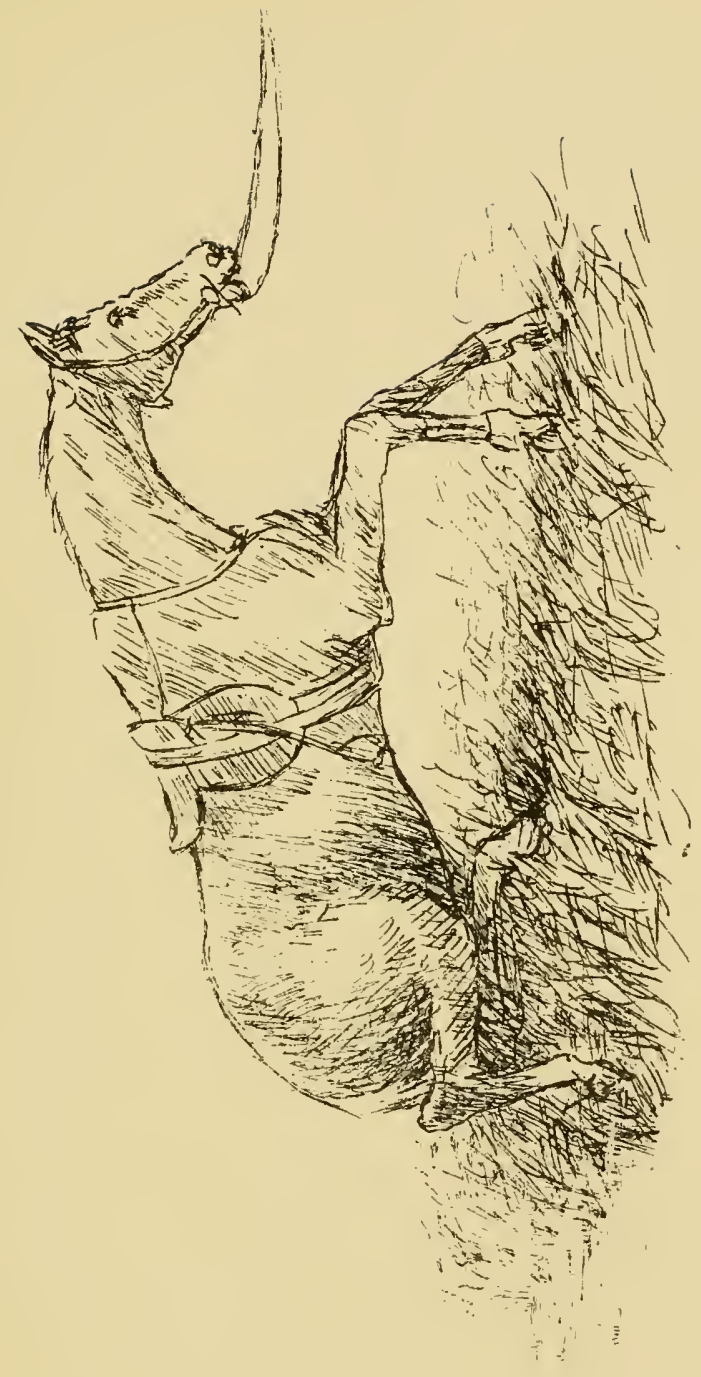



产 


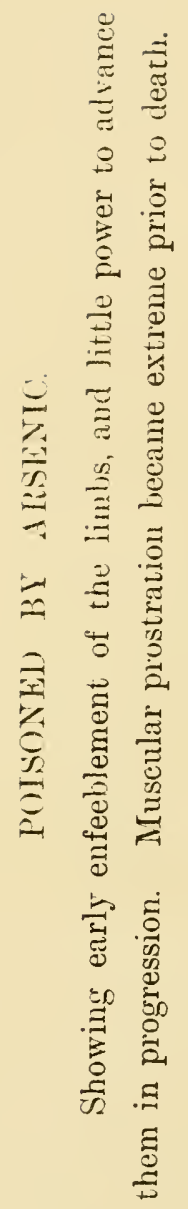




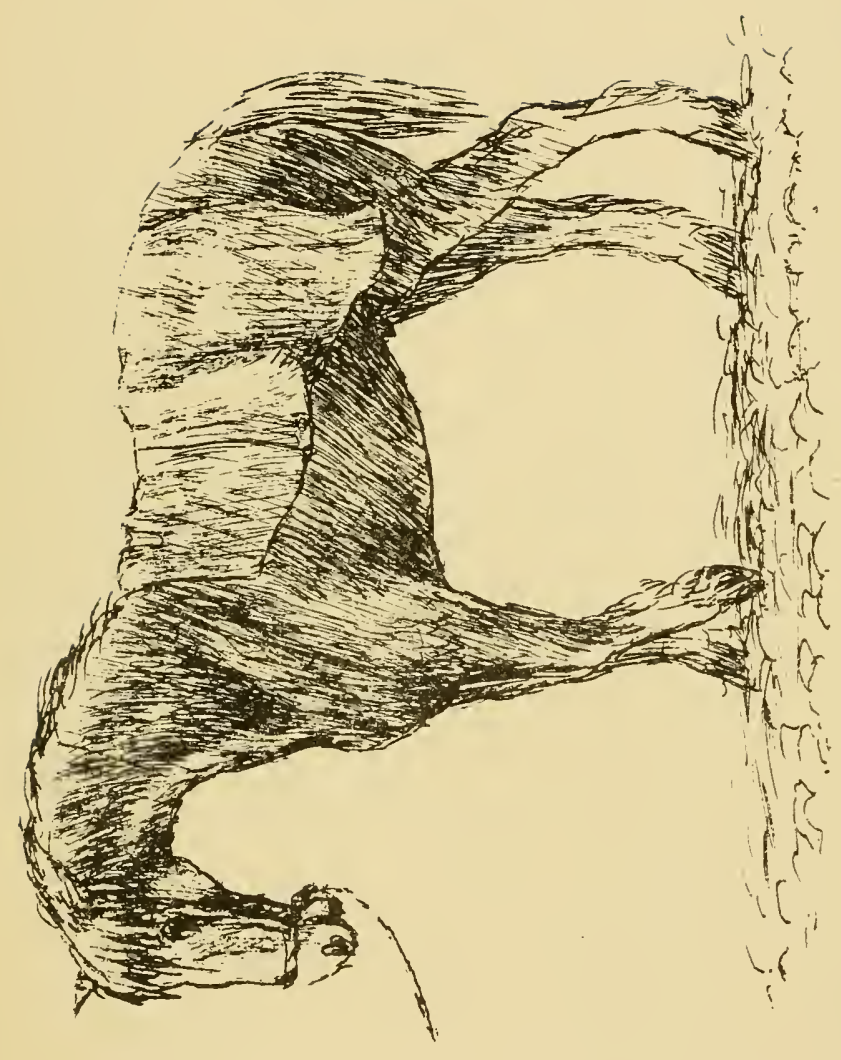



离
될 


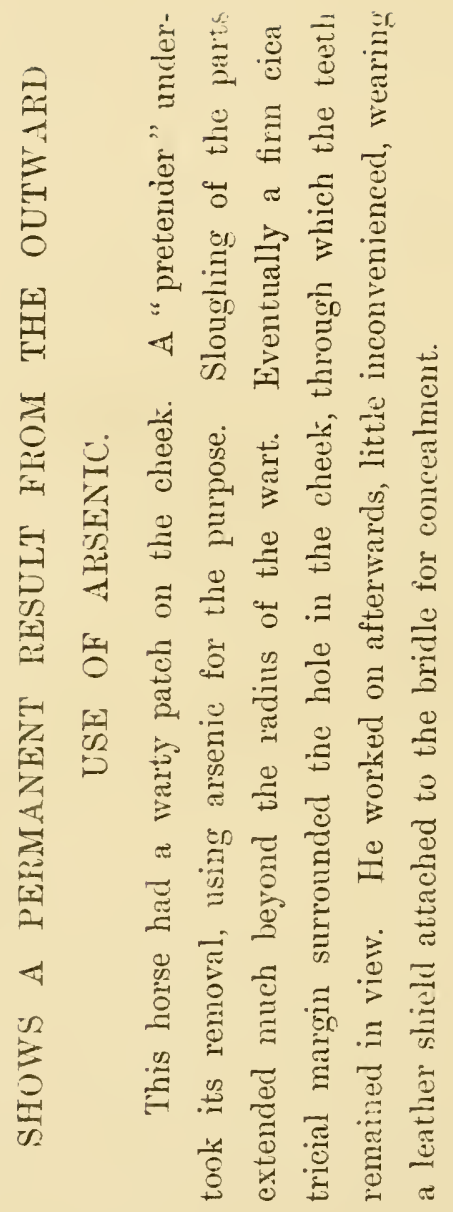




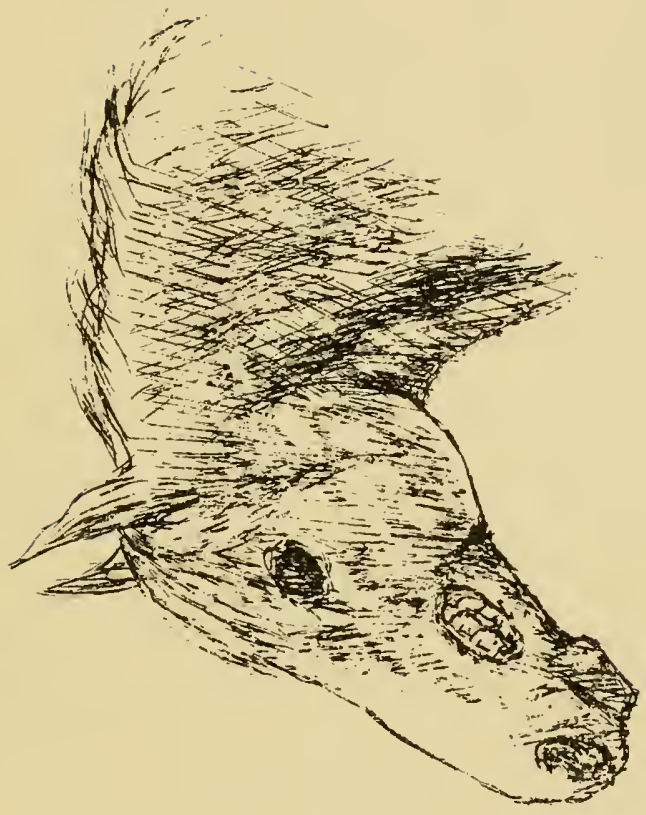





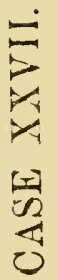




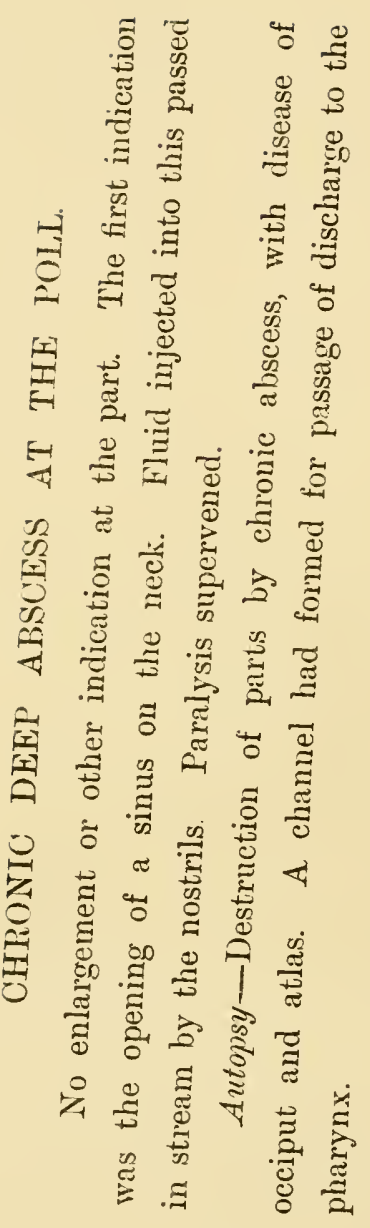




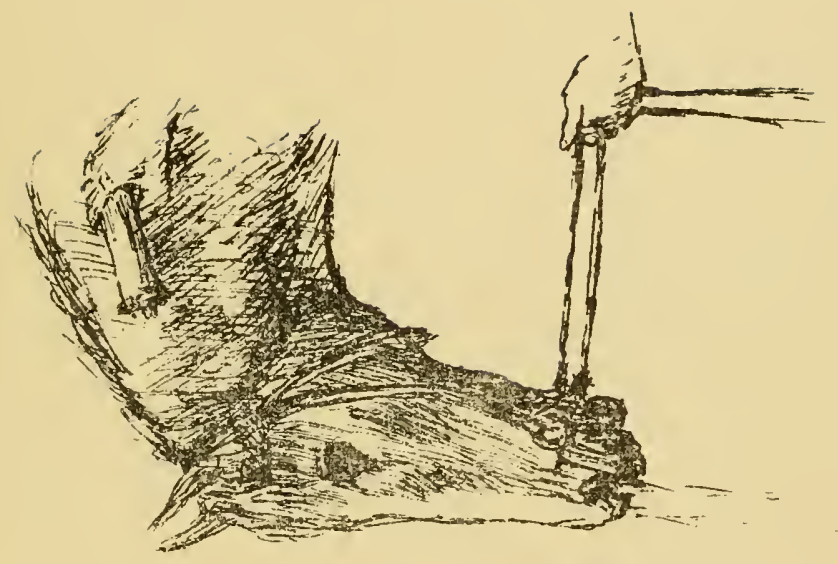



$\Xi$
$\vdots$
0
0
0 


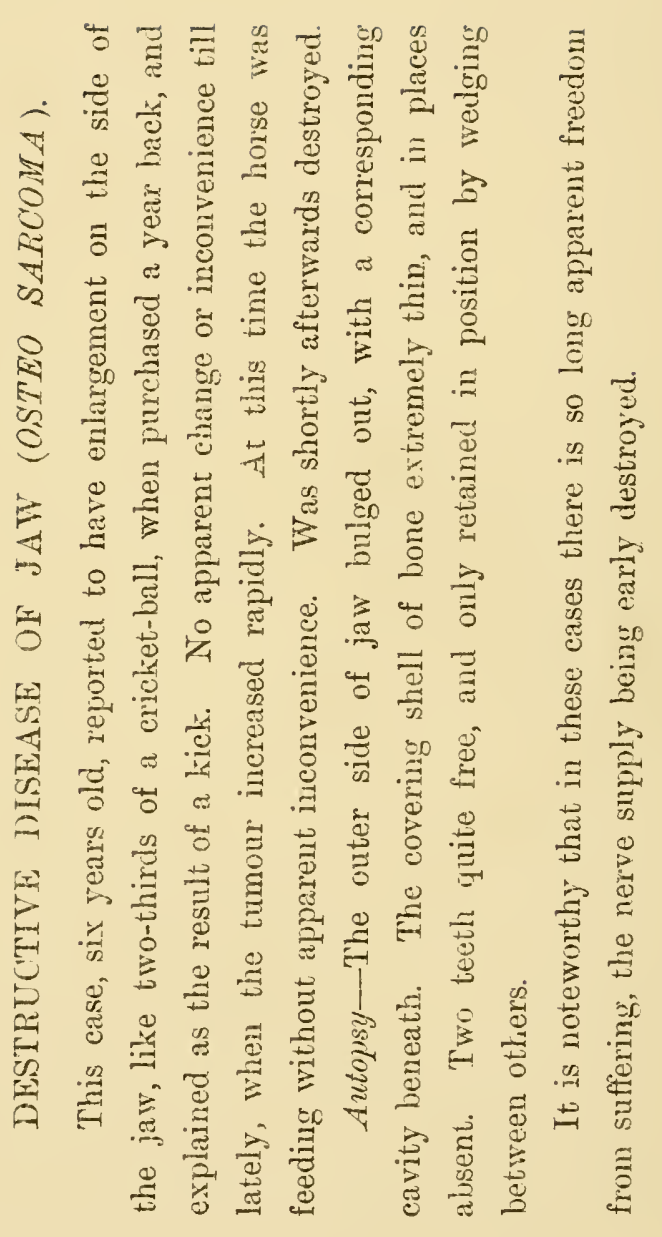



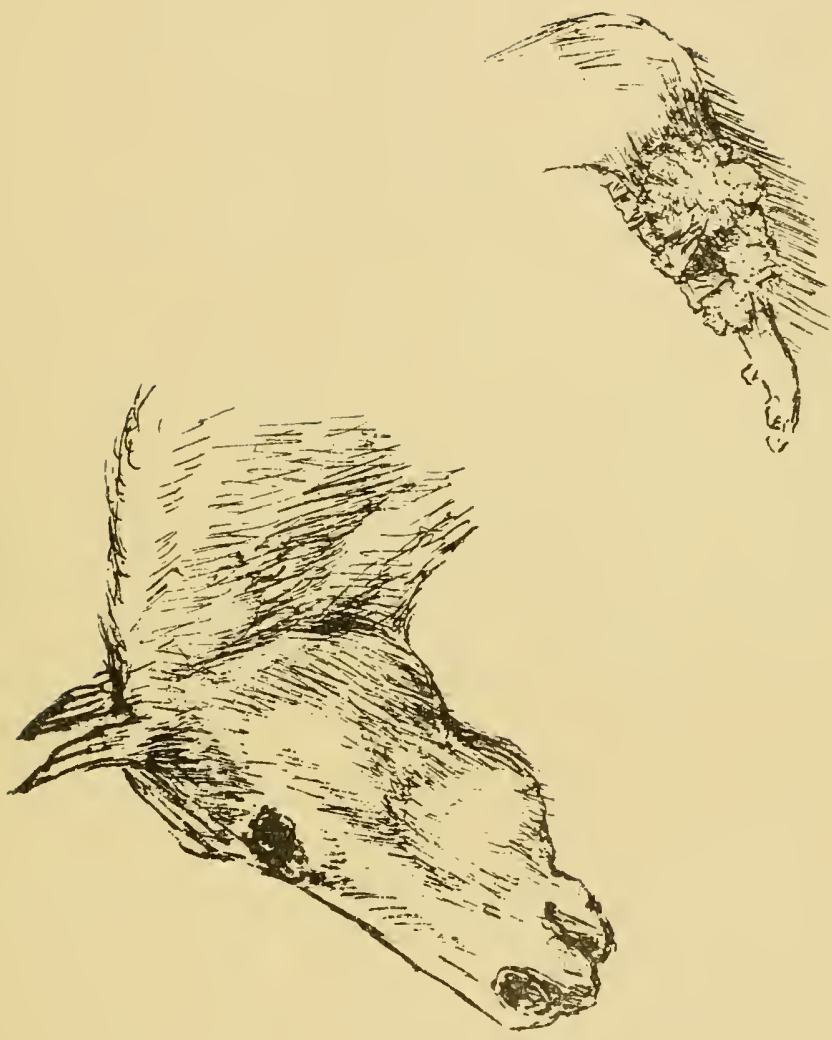




Webster Family Library of Veterinary Medicine Cummings School of Veterinary Medicine at

Tutts University

200 Westboro Road

North Grafton, MA 01536 

